\title{
THE POSSIBILITIES OF GIS DATABASE APPLICATION IN CHOSEN PRESENTATIONS OF REGIONAL GEOGRAPHIC CONTENTS IN THE PROCESS OF GEOGRAPHIC EDUCATION IN PRIMARY AND SECONDARY SCHOOLS IN BOSNIA AND HERZEGOVINA
}

DOI: http://dx.doi.org/10.18509/GBP.2015.19 UDC: 007:004.62]:528\}:373.3/.5(497.6)

\author{
Dr. Sc. Nusret Drešković, assistant professor \\ Dr. Sc. Ranko Mirić, assistant professor \\ Dr. Sc. Alma Pobrić, assistant professor \\ Boris Avdić, MA, assistant, PhD student \\ University of Sarajevo, Faculty of Science, Department of Geography - Bosnia and Herzegovina
}

\begin{abstract}
Contemporary research and presentation of regional geographic contents in primary and secondary schools are almost entirely based on application of adequate GIS databases, which are organized according to the structure of education process. Geographic databases are sets of digital geospatial data systematized at the level of related thematic spatial features that are organized in accordance to an adequate regional geographic fields contained in subject of Geography in primary and secondary schools. Geobases attributes should be adjusted to educational contents in specific teaching lessons. Structurally they are dominantly numerical. Textual and other attribute forms are aplicable only in the specific cases, when content and presentation of teaching lesson have such character. Especially important aspect in content and geobase structure organization is possibility of creation of new geospatial data on the basis of existing attributes, which are based on application of adequate geoprocessing models.

Geovisualization of an adequate attributive contents is based on structural GIS models for visualization, thereby putting thematic geobases contents into an adequate cartographic form, which enables automatic editing of all map elements. The tools for functional exploration of cartographic features are providing all the necessary prerequisites for achieving didactic objectives of contemporary geographic education process in primary and secondary schools.
\end{abstract}

Keywords: GIS, database, geographic education, Regional Geography, geoinformation.

\section{INTRODUCTION}

As a systematic science which studies natural and social components and their interaction and connections in certain area, Geography has a contemporary role in identification of intensity and time-space phenomena and processes. That role is especially significant in the aspect of defining optimal solutions in use of natural and social resources in environmental processes management as well as regional and spatial planning and geopolitical issues. Regarding mentioned contemporary significance and role of geographic science as one of the basic elements which defines implementation quality of 
given tasks, geographic education is vital component of contemporary general education. Education process in area of geographic science has full soundness at all levels of education - primary, secondary and tertiary, including graduate, postgraduate and $\mathrm{PhD}$ study. [2]

In accordance with contemporary pedagogic and didactic trends in general education, informatization of preparation, interpretation and presentation of educational contents became an integral part of teaching process at each aforementioned level of education. In that context, geographic science also has its particular IT expression called Geographic Information System (GIS), because of its fundamental purpose in the field of multi-user geospatial research.

In the present there are many GIS definitions, which content largely depends on category of users, working purpose and users experience in particular field. Basically, there are definition groups that explain GIS only partially (they are the most frequent ones), i.e. on the basis of just one or two its elements. One of those examples are numerous systems for mapping, which can be found on the market. There are many variations of those, from display systems like electronic atlases, to more sophisticated systems that include tools for visualization and partial organization of databases. Unlike these systems, advanced GIS applications have possibility to completely manage geodata in all aspects of its application: from adaptation, treatment and creation of thematic map sets to archiving and addition. Regarding these facts, one comprehensive definition say that "GIS represents information system (hardware, software, experts and data) designed for automatic graphical and numerical treatment of geographic data in the aspects of its input, (methodologically controlled) processing, presentation, output of final (printed and digital) products and digital archiving." [1]

\section{BASIC CHARACTERISTICS OF GIS}

Methodological concept of operation and process modules in GIS are now completely adjusted to research, understanding, critical thinking, presenting and sustainable management of every natural or social process and phenomenon in the field of geographic or other similar scientific disciplines. Unlike various information systems that only partially consider spatial reality (cartographically, graphically, statistically etc.), GIS applications enable complete organization process of geodata adaptation and treatment that includes: selection, organization, geoprocessing, geovisualization, research, distribution, storage and addition of data according to various classification criteria. Thereby, geovisualization of analyzed geodata is supported by process models and scripts which enable thematic cartographic data treatment with simultaneous preservation of dynamic relations with adequate bases.

Numerous tools for geostatistical work also enable multi criteria access in processing of existing and interpretation of obtained geodata and also their direct thematic cartographic adjustment. This level of work is provided by so-called layer organization which organizes geodata in topics and subtopics which are mutually connected in functional and structural order (figure 1). In this case, geodata are processed by an adequate application of geoprocess models and these new results and new geodata can be combined in order to get the other new results. Usage and processing of the same geodata is practically unlimited. This in the best way indicates the fact that GIS is an unlimited tool for continuous and advanced data collection and processing the most diverse sets of geospatial information. 


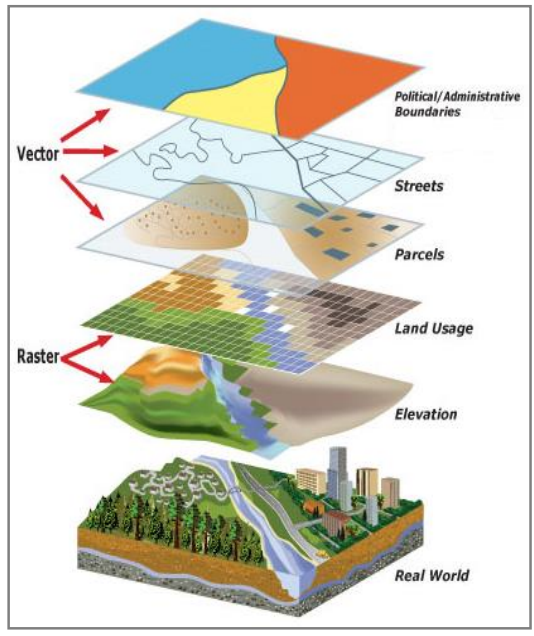

Figure 1: Layer organization of similar geodata types in GIS
Very important basic GIS property is completely relational access to geodata, i.e. it is possible to access geodata from graphic contents and vice versa, to access graphic contents from data geobase. One of the most significant aspects of GIS application are data. GIS data describe certain spatial reality in various aspects of interpretation. In accordance to that, usual name for this type of data is geodata whose records contain at least locational $(\varphi, \lambda$ and $\mathrm{H}$ or $\mathrm{x}, \mathrm{y}$ and $\mathrm{z}$ ) information. Data sources can have a graphical form (maps, pictures or videos) or a form of computer databases of various extensions, like Microsoft Excel, Lotus 1-2-3, dBase, mdb etc. Regardless data type, it is important to emphasize the fact that each of them has a certain attributive (descriptive) features which are more accurately defining and describing them, making them

usable for GIS analyses.

Regarding given objectives and work type, GIS operates with two basic data types: raster (picture) and vector (geometric data). Raster data are organized in so-called grid system, which basically consists of cells (pixels) that represents segments of spatial reality. In geographic and other similar research this type of geodata organization became crucial part in cartographic presentation of spatial reality, and it consists of different graphic formats, which vary from scanned and georeferenced general or thematic maps of various scale to aerial footage and satellite images. The main feature of aerial and satellite images is the size of represented spatial coverage and resolution (number of pixels per $\mathrm{cm}^{2}$ ). Most of these types of graphic data have its own attributive records, which are usually designated in numeric or code format.

Vector data type essentially represents the elements of computer graphics, which are obtained by manual, semi-automatic or automatic delineation. Basic structural forms of geometric data which represent certain spatial content are point, line and polygon. In any case, vector graphic data format are the carriers of quantitative and qualitative features of explored spatial phenomena. They are organized in adequate table records and attributive tables. It is important to notice that the most common form of table records are numerical and less common is textual table form. In recent period one of the inevitable data content in geobases are adequate photo and video records about researched phenomenon. This concept of numerical attributive properties organization enables application of numerous geostatistical process models and creation the most diverse and very complex digital sets of thematic data.

\section{GIS APPLICATION AND GEOGRAPHIC EDUCATION}

Contemporary education process in the subject of Geography in primary and secondary schools as well as on the geographic faculties is mostly based on geovisual and geoprocess modules of adequate GIS software. Base for application of these GIS modules are digital geodata collections organized in accordance to teaching themes and units in the form of various data attributes. [3] More precisely, structure of these data sets is conceptually adjusted to educational contents. In the field of Regional Geography these are presenting the physical and social spatial reality and processes at the level of individual countries and world regions. Organization of digital geographic data is 
adjusted in accordance to the curricula for primary and secondary schools. Digital geodatabases which treat regional geography issues are contained in a number of different digital media and are mostly organized in accordance to this concept. One of the most important electronic data sources is ESRI's digital atlas of the world and continents, which contains different physical and social geographical data.

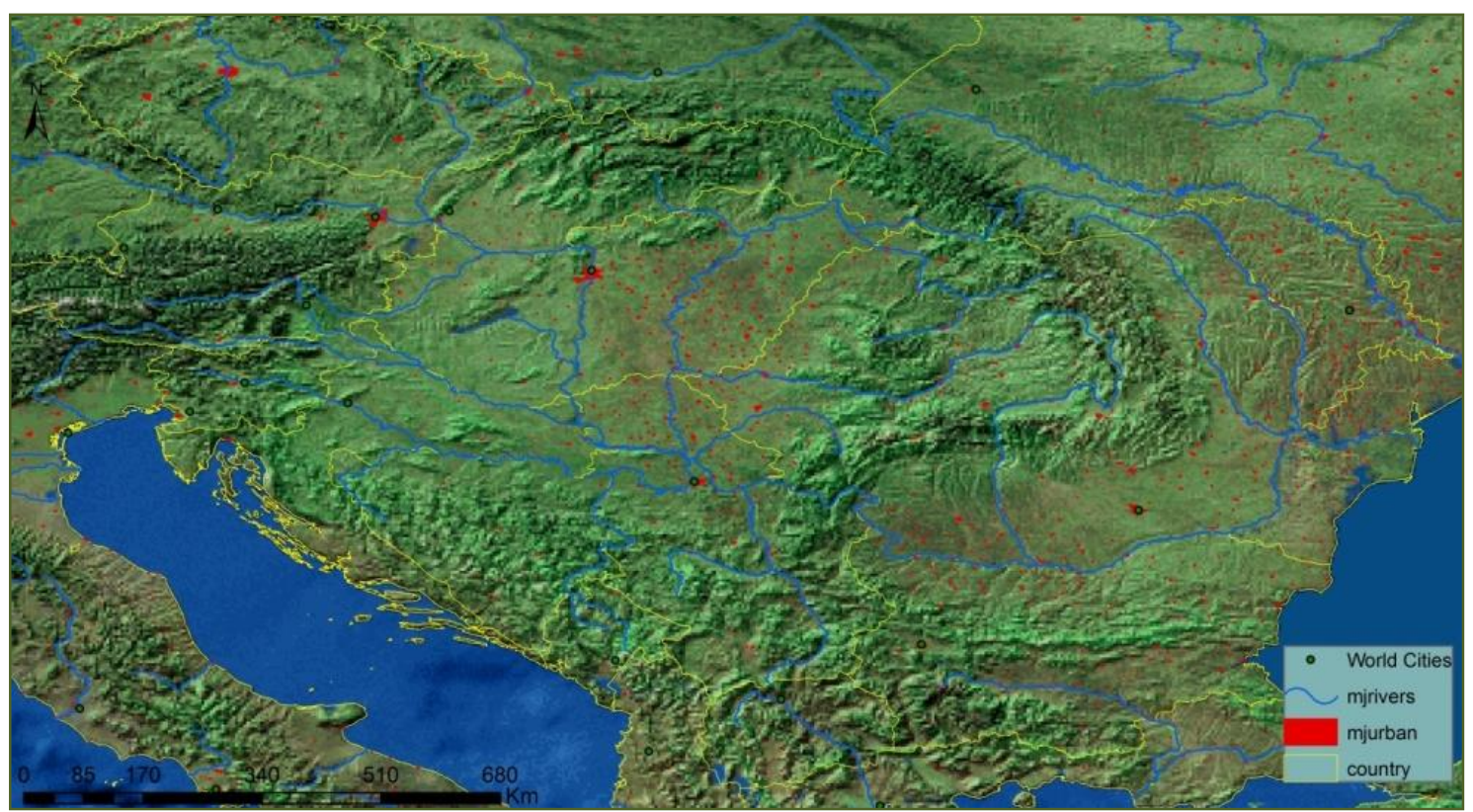

Figure 2: Display of geographic contents of the portion of Central and Southern Europe region by combining sets of thematic raster and vector data

For study field of Earth, its terrain and land cover types, a digital model of the Earth is largely used in the teaching process. This model is made in a small spatial resolution of $10 \times 5 \mathrm{~km}$ so it is suitable for representing relief of continents and their individual geographic regions (figure 2). Combined with vector contents, it can be used to display borders of individual states, spatial coverage and the size of the individual states, cities, large rivers and lakes etc. In this way the motivation to learn increases among the student population while constructive thinking and reasoning significantly enhances during the process of clarifying certain combined contents. For the presentation of content in the field of human geography of continents, regions and countries, there is a huge collection of datasets which are treating certain thematic teaching areas. A special aspect of digital atlas application in presentation of base regional geography teaching contents is the possibility of interactive learning by using the appropriate GIS tools for query and calculation. [4] 


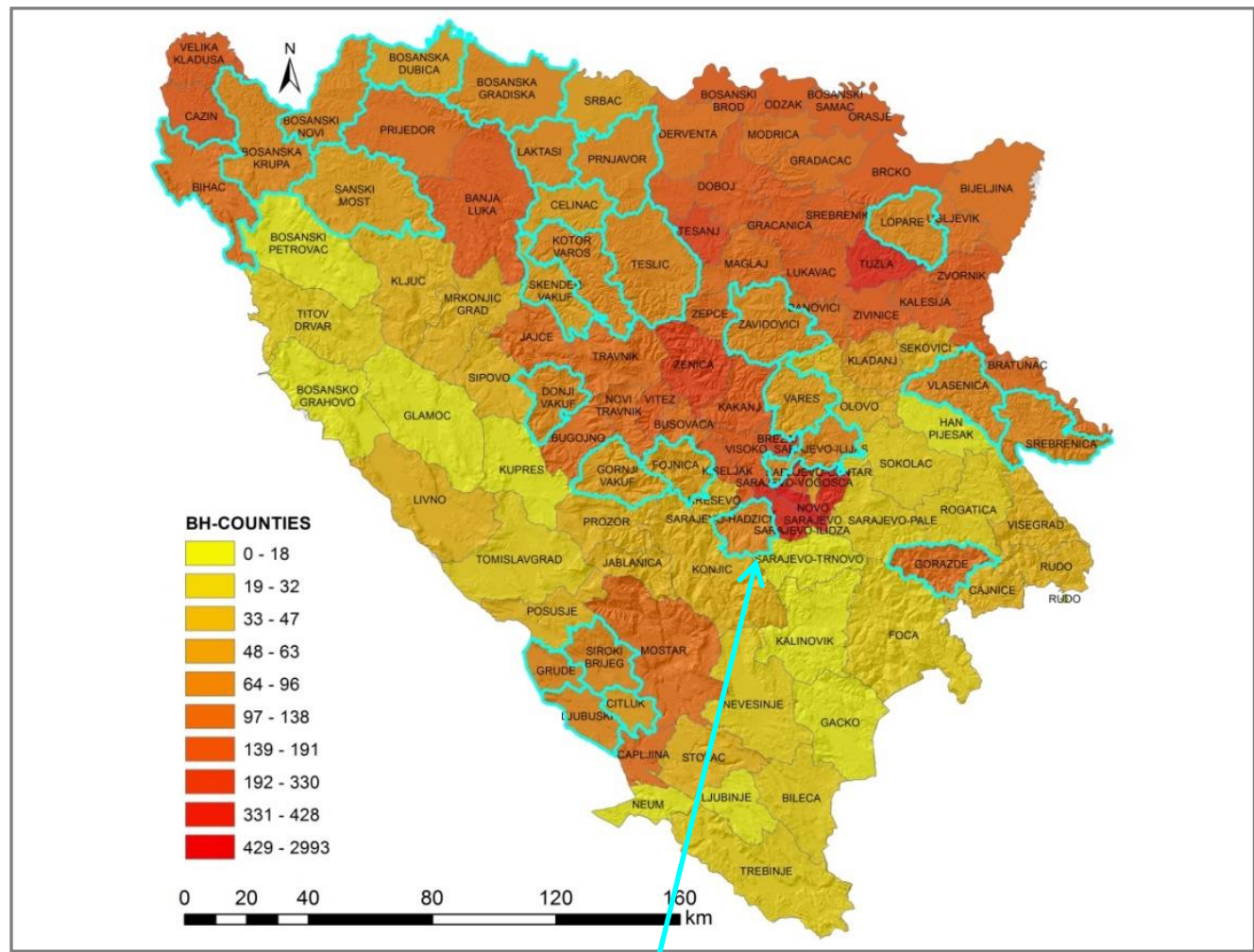

\begin{tabular}{|c|c|c|c|c|c|c|c|c|c|c|c|}
\hline & NAME & NO PLACES & DENSITY & POP 71 & POP 81 & P & MOSLEMS91 & $\begin{array}{l}\text { SERBS91 } \\
\end{array}$ & CROATS91 & MOSLEMS81 & \begin{tabular}{ll|} 
SERBS81 \\
\end{tabular} \\
\hline & NOVO SARAJEVO & 8 & 1969 & 111811 & 94200 & 95089 & 33902 & 32899 & 8798 & 26634 & 31276 \\
\hline & SARAJEVO-HADZICI & 62 & 88,7 & 18508 & 20952 & 24200 & 15392 & 6362 & 746 & 12406 & 5778 \\
\hline & SARAJEVO-TRNOVO & 63 & 14,3 & 9555 & 8161 & 6991 & 4790 & 2059 & 16 & 5693 & 2242 \\
\hline & JABLANICA & 33 & 42,1 & 10938 & 11903 & 12691 & 9099 & 504 & 2291 & 7806 & 512 \\
\hline & RUDO & 89 & 33,5 & 15982 & 13601 & 11571 & 3130 & 8150 & 5 & 4382 & 8699 \\
\hline & GORAZDE & 187 & 99,6 & 34685 & 36924 & 37573 & 26296 & 9843 & 80 & 25142 & 9107 \\
\hline & FOCA & 120 & 31,5 & 48741 & 44661 & 40513 & 20790 & 18315 & 94 & 23316 & 18908 \\
\hline & CAJNICE & 36 & 33,6 & 11602 & 10280 & 8956 & 4024 & 4709 & 5 & 4880 & 4892 \\
\hline & POSUSJE & 19 & 38,7 & 16882 & 16455 & 17134 & 6 & 9 & 16963 & 15 & 34 \\
\hline & KALINOVIK & 73 & 5,9 & 9458 & 6597 & 4667 & 1716 & 2826 & 17 & 2681 & 3691 \\
\hline & MOSTAR & 57 & 103,7 & 89580 & 110377 & 126628 & 43856 & 23846 & 43037 & 34247 & 20271 \\
\hline & RUDO & 0 & 0 & 0 & 0 & 0 & 0 & 0 & 0 & 0 & 0 \\
\hline & SIROKI BRIEG & 35 & 71 & 27285 & 26076 & 27180 & 9 & 148 & 26884 & 7 & 180 \\
\hline & NEVESINJE & 56 & 19,9 & 19333 & 16326 & 14448 & 3313 & 10711 & 210 & 3853 & 11587 \\
\hline & GRUDE & 13 & 74,6 & 19203 & 17767 & 16358 & 4 & 9 & 16210 & 4 & 35 \\
\hline
\end{tabular}

Figure 3: Selecting the content and relational two-way relationship between graphic and adequate records in the accompanying geodatabase (Source: Digital atlas of Bosnia and Herzegovina)

Set of the aforementioned tools is based on the analysis of a geodatabases that monitors the specified graphic content and is widely applied in order to augment students' motivation and also in order to increase the specific knowledge of the spatial reality in a given teaching area. It is possible to assign virtually unlimited queries per a certain criterion by using advanced tools for selection. This way students can extract the certain contents and geovisualize them by using an existing theme or by creating the new one all in accordance to teacher instructions or independently during the learning process. Special importance in the preparation and presentation of the teaching units have tools for different topological analysis which can combine data from two different thematic layers and thus create new geodatabases. It is also important to emphasize that these processes are providing the possibility of combining different sets of data contained in the formats of raster and / or vector type.

\section{KRIGING MODEL OF SPATIAL INTERPOLATION}


Not considering issues of structural GIS concept and its user interface, for the purpose of geographic study in this paper are used processing modules for advances spatial analyses by application of various GIS spatial analyzers. More specifically, GIS based analytical modules for spatial analysis now have inevitable application in research and interpretation of component physical and human geographic contents in school Geography as well as in various geographic applications and types of research. [5] After multiple testing of various subprocessing models, only limited number of them have shown itself as acceptable enough, mostly because their script models was able to support interpolation processes by combining the basic with additional data sets. More specifically, in topographic and geostatistical aspects only the following GIS based models of spatial interpolation yielded acceptable results:

- Inverse Distance Weighting - IDW

- Spline model

- Kriging model.

Kriging interpolation model is selected as functionally and spatially the most adaptable through additional detailed analysis. Kriging model is advanced geostatistical procedure that extracts estimated surface from dispersed set of points with z-values. This method is based on regionalised variable theory, assuming that spatial variation of analyzed parameter presented as z-value is statistically homogenous on the whole area. Spatial homogeneity hypothesis is the base for regionalized variables theory. Interpolation process includes interactive research of spatial behavior of analyzed data represented by z-values, before the selection of the best estimation method for output surface. Spatial variation is quantified by semi-variogram. The semi-variogram is estimated by its sample, which is calculated from number of input point data sets. Its sample value for separate distance $h$ is average square difference in $\mathrm{z}$-value between the pairs of input sample points separated by h. Semi-variogram sample is calculated by equation:

$$
\hat{Z}\left(s_{0}\right)=\sum_{i=1}^{N} \lambda_{i} Z\left(s_{i}\right)
$$

$\mathrm{Z}(\mathrm{si})$ - measured value of pairs of points at i location;

$\lambda i \quad$ - unknown weight of measured value of pairs of points at i location;

s0 - predicting location;

$\mathrm{N} \quad$ - number of measured values of pairs of points separated by distance $\mathrm{h}$.

Kriging model offers two surface interpolation methods: Regular Kriging and Universal Kriging, both of which having its specificities with respect to semi-variogram model. Krining interpolation model output has GRID format. GRID is basic raster format of data storage in ESRI software environment, represented by two types: integer and floating. GRIDs are organized as a grid structure, where basic sets of stored data are represented by grid cells. Number of grid cells is highly variable and depends on numbers of rows and columns, and in total can reach multiple million.

Aforementioned model is applicable practically in all fields of geographic spatial research as well as in presentation of various regional thematic contents. In this paper, Kriging interpolation model is used for making thermic model for Bosnia and Herzegovina, i.e. 
for making and visualization of spatial distribution of annual mean air temperature. This spatial model is made by taking of temperature data from network of regular and additional (hypothetic) stations for measuring air temperature, with the validation of analysed data by using the Digital Elevation Model (DEM) for the territory of Bosnia and Herzegovina in 20-meter resolution. Default surface interpolation of data about annual mean air temperature is based on two subprocessing methods. First one in basic, and is based on neighborhood research of (defined maximum) 200 locations of temperature stations and taking data from them. Second subprocessing model is validation one. In spatial modeling, it runs interpolation research that defines vertical thermic gradient. In other words, this model gives to each grid cell a temperature value that is based on relation between air temperature and altitude of temperature stations. By application of Kriging modeling, spatial thermic model of high accuracy for annual mean air temperature is made in GRID format. Considering that 20-meters resolution DEM is used in validation analyses, output of thermic model for Bosnia and Herzegovina is made in the same resolution (figure 4).

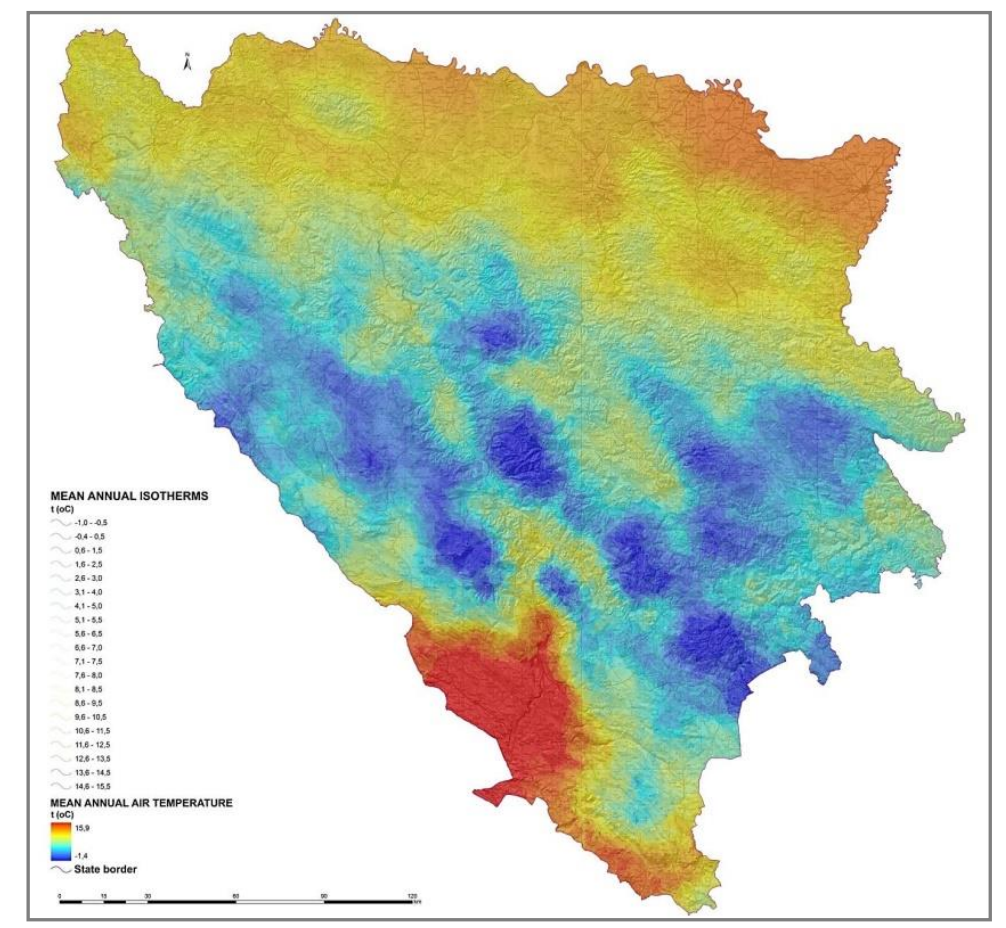

Figure 4: Annual isotherms and thermic model of air temperatures in Bosnia and Herzegovina

By analysis of data geobase of thermic model of annual temperature, students will get information that annual mean air temperature for the territory of Bosnia and Herzegovina is $10,9^{\circ} \mathrm{C}$, with notion about significant differences between two existing climate belts. More precisely, in the region of northern temperate climate belt, value of annual mean air temperature is around $9,7^{\circ} \mathrm{C}$, while in Mediterranean climate zone this value is equal to $12,1^{\circ} \mathrm{C}$. Thermic contrasts are very strong, considering that mean temperature in areas of highest mountain peaks is negative $\left(-1,4^{\circ} \mathrm{C}\right.$ at the Mount Maglić), while in the coastal area of Neum it is $15,9^{\circ} \mathrm{C}$. It is important to emphasize that this thermic difference of nearly $18^{\circ} \mathrm{C}$ is established on the horizontal distance of only 85,5 kilometers (Mount 
Maglić - Bay of Župa). Average difference per kilometer is $0,21^{\circ} \mathrm{C}$, and it is more than 30 times greater than average horizontal temperature change in the northen hemisphere. This climatic specificity is the result of morphological and morphometrical relations, because average slope gradient on the aforementioned profile is approximately $30 \mathrm{~m} / \mathrm{km}$.

\section{CONCLUSION}

On the basis of exposed indicators about challenges of contemporary education process in school Geography, it is formed a conclusion about GIS as very helpful system of digital tools in planning and implementation of education contents. Conducted analyses of selected examples showed the possible methods of GIS modules application in presentation of regional geographic contents at the level of regular and facultative geographic courses. In accordance with that, it could be said that GIS spatial interpolators have unlimited possibilities in geographic research and implementation of its results in education process.

\section{LITERATURE}

[1] Drešković, N., Đug, S. Applying the Inverse Distance Weighting and Kriging methods of The spatial interpolation on the Mapping the Annual Precipitation in Bosnia and Herzegovina. International Environmental Modelling and Software Society (iEMSs). International Congress on Environmental Modelling and Software Managing Resources of a Limited Planet, Sixth Biennial Meeting, Leipzig, Germany, 2012.

[2] Freeman, D. GIS in secondary geography. Teaching Geography, Project of Geographic Association of United Kingdom, 2003.

[3] Johansson, T. GIS in teacher education - facilitating GIS applications in secondary school geograph. Helsinki, 2003.

[4] Kemp, K., Goodchild, M.F., Dodson, R.F. Teaching GIS in geography. InterScience Wiley, 1992.

[5] Wiegand, P. Geographical Information Systems (GIS) in Education. International Research in Geographical and Environmental Education, Vol. 10, 2001. 